\section{Detección y diferenciación de Entamoeba histolytica y Entamoeba dispar mediante reacción en cadena de la polimerasa en individuos de una comunidad del Estado Zulia, Venezuela}

\author{
Detection and differentiation of Entamoeba histolytica \\ and Entamoeba dispar by polymerase chain reaction \\ in a community in Zulia State, Venezuela
}

\footnotetext{
${ }_{1}^{1}$ Escuela de Bioanálisis, Universidad del Zulia, Maracaibo, Venezuela. $\uparrow$ Fallecido.

Correspondencia Z. Rivero

Cátedra de Práctica Profesional de Parasitología Escuela de Bioanálisis, Facultad de Medicina, Universidad del Zulia. Urb. La Rotaria, Av. 87 \#82-36, Maracaibo, Venezuela.

zulbeyrivero@cantv.net
}

\begin{abstract}
Differential identification of Entamoeba histolytica and Entamoeba dispar is essential for both appropriate patient treatment and epidemiological purposes. To determine the prevalence of these amoeba infections in Santa Rosa de Agua (Maracaibo, Zulia State, Venezuela), a PCR assay using specific primers for each species was standardized and applied. 204 stool samples were analyzed through direct microscopic examination with SSF (0.85\%) and lugol, formol-ether concentration, and PCR. Under direct microscopy, 42 individuals (20.58\%) presented the $\mathrm{E}$. histolytica/E. dispar complex. Meanwhile PCR showed 47 positive cases for these amoebas: $22 \mathrm{E}$. histolytica (10.78\%), 16 E. dispar (7.84\%), and 9 (4.41\%) mixed infections. There was no significant difference in the presence of $\mathrm{E}$. histolytica and/or E. dispar according to either gender or age. There were no cases of these amoebas in children under 2 years of age. Observed frequency of E. histolytica (31/204) shows the endemic nature of amoeba infection in this community.
\end{abstract}

Entamoeba; Parasites; Feces; Microscopy; Polymerase Chain Reaction
Zulbey Rivero 1

Ángela Bracho 1

Marinella Calchi 1

Iris Diaz ${ }^{1}$

Ellen Acurero ${ }^{1}$

Adriana Maldonado 1

Glenis Chourio 1

Nailet Arráiz 1

Gilbert Corzo \%

\section{Introducción}

El término amibiasis define todos los casos de infección humana por Entamoeba histolytica, independientemente de la presencia o ausencia de manifestaciones clínicas en el individuo. A lo largo del tiempo, se acumularon múltiples incógnitas relacionadas con las variaciones de casos sintomáticos y asintomáticos en los pacientes infectados con esta amiba. Esto generó la propuesta de la existencia de cepas patógenas y no patógenas de E. histolytica 1,2,3, así como la existencia de dos especies diferentes, pero con idénticas características morfológicas ${ }^{4}$. Múltiples estudios bioquímicos, inmunológicos y genómicos permitieron que finalmente en el año 1997, durante el XIII Seminario sobre la Amibiasis en la Ciudad de México, los expertos reconocieran la existencia de dos especies diferentes de Entamoeba: E. histolytica como la especie causante de enfermedad invasiva y extra-intestinal y E. dispar como la especie no patógena ${ }^{5}$. La aceptación de la existencia de E. dispar cambia drásticamente la epidemiología de la amibiasis y conlleva a que las estimaciones sobre la prevalencia real de $E$. histolytica a nivel mundial sean reinterpretadas.

A pesar de haberse esclarecido esta situación, permanecen en la actualidad una serie de problemas relacionados con el diagnóstico de la amibiasis. Por un lado, el desconocimiento de la nueva clasificación por parte de muchos profesionales del área de la salud, y por otro, la me- 
todología de laboratorio que ahora es necesaria para la diferenciación de E. histolytica y E. dispar. El diagnóstico rutinario de amibiasis se realiza mediante examen coprológico, generalmente con la observación microscópica de quistes y/ o trofozoítos característicos en las heces o con menos frecuencia en la biopsia de tejido mucoso ${ }^{6}$. Sin embargo, el examen microscópico del material fecal tiene varias limitaciones, la más importante de ellas es la incapacidad de distinguir entre E. histolytica y E. dispar, debido a que son morfológicamente idénticas, y sólo puede confirmarse la presencia de E. histolytica cuando las heces presentan trofozoítos hematófagos 7. Además, el examen microscópico es sumamente subjetivo, dependiendo en alto grado de la pericia del observador en diferenciar la morfología del protozoario de la morfología de otras especies de amibas comensales tales como: E. coli, E. hartmanni, Iodamoeba butschlii o Endolimax nana, así como de otros elementos como leucocitos y macrófagos y no dar lugar a sobre-diagnósticos de amibiasis. Por todo lo anteriormente expuesto, es imperativo reconocer que deben realizarse pruebas especiales, como las técnicas de detección de antígenos específicos de E. histolytica o técnicas de reacción en cadena de la polimerasa (PCR) para poder discriminar la presencia de $E$. histolytica y/o E. dispar en las heces de un paciente determinado.

Lamentablemente las deficientes infraestructuras y bajos presupuestos existentes en los centros de salud públicos regionales, limitan la aplicación de dichas técnicas en los laboratorios. Esta dificultad ha impedido establecer la verdadera prevalencia de la amibiasis en el estado y en el país. Esta investigación pretende estandarizar una técnica de PCR que permita identificar y diferenciar E. histolytica y E. dispar en individuos de una comunidad del municipio Maracaibo, Estado Zulia, Venezuela, como estudio pionero en la determinación exacta de la prevalencia de estas amibas en nuestra región.

\section{Materiales y métodos}

\section{Población}

Fue realizado un estudio descriptivo, no experimental en individuos de la comunidad de Santa Rosa de Agua, en el periodo comprendido desde enero hasta julio de 2006. Santa Rosa se ubica en la región nor-este del municipio Maracaibo; dicha comunidad está dividida geográficamente en dos sectores: tierra y agua, esto significa que algunas viviendas están construidas sobre tierra firme y otras sobre el agua (palafitos). Los factores que influenciaron la elección de esta comunidad fueron, la dimensión de la misma, sus precarias condiciones higiénico-sanitarias y la proximidad a la Universidad del Zulia. Como criterio de inclusión se exigió el no haber ingerido medicamentos antiparasitarios como mínimo, seis meses antes de la toma de la muestra. Se obtuvo el consentimiento escrito de los padres, representantes o jefes de familia de la comunidad, lo que permitió que 204 individuos aceptaran participar en el estudio y cumplieran con los requerimientos del mismo. Cada familia fue entrevistada por un miembro del equipo de investigación, así mismo le fue explicado el propósito del estudio, el tipo de muestra requerida y su correcta recolección.

Como colaboración a la comunidad, los individuos parasitados recibieron tratamiento antihelmíntico de forma gratuita, posterior al diagnóstico parasitológico y clínico, que fue realizado por dos médicos de la Universidad del Zulia.

\section{Muestras y procedimiento parasitológico}

Se recolectó un espécimen fecal por individuo, en un envase plástico grande, nuevo, limpio, de boca ancha y tapa de rosca. Estas muestras se mantuvieron refrigeradas $\left(4^{\circ} \mathrm{C}\right) \mathrm{y} \sin$ tratamiento químico alguno, hasta su procesamiento en el Laboratorio de Parasitología de la Escuela de Bioanálisis de la Universidad del Zulia. Cada muestra fue dividida en dos partes, una de ellas se congeló a $-20^{\circ} \mathrm{C}$, para su posterior análisis molecular (PCR) y la otra porción se mantuvo sin congelar para el análisis parasitológico. Este consistió en el montaje al fresco con SSF y lugol, así como el método de concentración de formol-éter 8 , para identificar la presencia de alguna forma evolutiva de Entamoeba.

\section{Caracterización molecular de} E. histolytica y E. dispar

La extracción de ADN genómico de Entamoeba sp. a partir de muestras de heces, se llevó a cabo a través de un procedimiento estandarizado en el laboratorio que incorporó algunos pasos de protocolos de lisis enzimática, choque térmico y mecánico, descritos previamente 9,10,11. Se transfirió aproximadamente de 0,5 a $0,7 \mathrm{~g}$ de heces a un tubo Eppendorf de $2 \mathrm{~mL}$, se resuspendió en $1 \mathrm{~mL}$ de $\mathrm{PBS}\left(0,1 \mathrm{M} \mathrm{Na} \mathrm{HPO}_{4}, 0,1 \mathrm{M} \mathrm{NaH} \mathrm{PO}_{4}\right.$, $\mathrm{pH} 7,5)$ y se filtró a través de doble malla de gasa estéril. El homogeneizado fue centrifugado a 10.000rpm y el sedimento resultante fue lavado tres veces con 1,5mL de PBS para eliminar contaminantes solubles. El sedimento resultante se lavó con $1 \mathrm{~mL}$ de $\mathrm{NaCl} 0,15 \mathrm{M}$ tres veces o hasta que el sobrenadante quedó claro. El sedimento 
se resuspendió en $600 \mu \mathrm{L}$ de buffer de lisis (Tris-Cl $100 \mathrm{mM} \mathrm{pH} 8,25 \mathrm{mM}$ EDTA, $0,25 \%$ SDS) y se sometió a 5 ciclos de congelación-descongelación, incubando el tubo en hielo seco-alcohol isopropílico por 5 minutos y descongelando a $37^{\circ} \mathrm{C}$ por tres minutos. Después del último tratamiento, se agregó $10 \mu \mathrm{L}$ de proteinasa $\mathrm{k}$ de $20 \mathrm{mg} / \mathrm{mL}$ y se incubó a $55^{\circ} \mathrm{C}$ durante toda la noche. $\mathrm{Al}$ día siguiente, se agregó $60 \mu \mathrm{L}$ de CTAB- $\mathrm{NaCl}(0,7 \mathrm{M}$ $\mathrm{NaCl}, 1 \% \mathrm{CTAB}$ ) y se incubó a $65^{\circ} \mathrm{C}$ por una hora. Se hizo una extracción con $500 \mu \mathrm{L}$ de cloroformo, luego con fenol-cloroformo y cloroformo. Se recuperó la fase acuosa en otro tubo Eppendorf y el ADN se precipitó con $600 \mu \mathrm{L}$ de isopropanol, incubándolo a temperatura ambiente durante 45 minutos y luego centrifugando durante 30 minutos a 14.000rpm. El sedimento se resuspendió en $50 \mu \mathrm{L}$ de buffer TE. Se utilizó $10 \mu \mathrm{L}$ de la muestra para ensayos de amplificación. El mismo tratamiento fue seguido para la extracción de ADN genómico a partir de cultivos de E. histolytica IULA:1092:1. En estos casos se utilizó 2,5 $\mathrm{LL}$ de ADN para los ensayos de amplificación por PCR de los controles.

Se preparó una mezcla de reacción para un volumen final de $50 \mu \mathrm{L}$, consistiendo en $10 \mu \mathrm{L}$ de buffer Go taq DNA polimerasa 10X (Promega), 2,5mM $\mathrm{MgCl}_{2}, 200 \mu \mathrm{M}$ cada desoxirribonucleótido (dATP, dCTP, dGTP y dTTP), $1 \mu \mathrm{L}$ de cada oligonucleótido (primers) $50 \mu \mathrm{M}(1 \mu \mathrm{M}$ cada oligonucleótido). Se utilizó $0,5 \mu \mathrm{L}$ de Taq DNA polimerasa $5 \mathrm{U} / \mu \mathrm{L}$ para cada reacción. Esta mezcla de reacción se utilizó para amplificación por PCR de secuencias del gen SRPEh $5 \backslash$ '-> CTT GAA AAG CTT GAA GAA GCT G 3\'; 3\'AAC AAT GAA TGG ACT TGATGCA -<5 \'; y SRPEd 5।'-> GTA GTT CAT CAA ACA CAG GTG A 3\'; 3\' CAA TAG CCA TAA TGA AAG CAA -<5 \’; incluyendo los oligonucleótidos específicos para cada reacción. Para la amplificación de secuencias del genoma de E. histolytica y E. dispar, se utilizaron dos pares de oligonucleótidos dirigidos a la secuencia del gen SREHP, cuya especificidad ha sido reportada previamente 10. El gen SREHP codifica para una proteína antigénica rica en serina en ambas especies 12 y la identidad de los oligonucleótidos utilizados fue confirmada por alineamiento de sus secuencias, utilizando el programa Blast y las bases de datos del National Center for Biotechnology Information (NCBI) de los Estados Unidos 13,14. Los oligonucleótidos fueron sintetizados por Maxim Biotech (Rockville, Estados Unidos).

Para los oligonucleótidos SRPEh5/3, específicos de E. histolytica, el programa de amplificación definitivo fue modificado del protocolo previamente reportado 15 , consistió en una desnaturalización inicial de 10 minutos a $96^{\circ} \mathrm{C}$ y 35 ciclos de amplificación de 1 minuto a $94^{\circ} \mathrm{C}$ (des- naturalización), 1,5 minuto a $64^{\circ} \mathrm{C}$ (alineamiento de los oligonucleótidos) y 2 minutos a $72^{\circ} \mathrm{C}$ (polimerización). Se incluyó un paso final de extensión a $72^{\circ} \mathrm{C}$ por 8 minutos.

Para los oligonucleótidos SRPEd5/3, específicos de E. dispar, se utilizó un programa equivalente al anterior (SRPEh5/3), pero cambiando la temperatura de alineamiento de los oligonucleótidos a $60^{\circ} \mathrm{C}$, a partir del protocolo descrito por Ramos et al. 10 .

Los oligonucleótidos SRPEd5/3 son específicos de E. dispar y generan un fragmento de $567 \mathrm{bp}$, mientras que los oligonucleótidos SRPEh5/3 específicos de E. histolytica generan un fragmento de $553 \mathrm{pb}$.

La preparación de las mezclas de PCR se llevó a cabo en un área de trabajo estéril y para las reacciones de amplificación se utilizó un termociclador MJ Research PTC-100 (GMI Inc.). En todos los ensayos se incluyeron controles negativos y positivos. Como control negativo, se utilizó la mezcla de reacción sin el ADN blanco. Como controles positivos se utilizaron 2,5 $\mu \mathrm{L}$ del ADN extraído a partir del cultivo de E. histolytica IULA:1092:1 (según el mismo protocolo anteriormente descrito) y como control positivo de E. dispar se utilizaron $2,5 \mu \mathrm{L}$ del ADN genómico que nos fue donado por el Centers for Disease Control and Prevention (CDC) de los Estados Unidos.

Los productos de PCR se separaron en geles de agarosa en cámaras horizontales (Bio-Rad Laboratoires). La concentración de agarosa utilizada fue de $1 \%$. Como buffer de corrida se utilizó TBE (Tris-Borato 89mM, EDTA 2mM pH 8). La corrida se llevó a cabo a $40 \mathrm{v} / \mathrm{cm}$ por $2-3$ horas. Los geles fueron teñidos con bromuro de etidio, visualizados en transiluminador ultravioleta y fotografiados con sistema de fotodocumentación DigiDoc UVP. Se incluyó marcador de peso molecular 100bp DNA Ladder de Promega.

\section{Análisis estadístico}

Para el análisis se utilizó el paquete estadístico Statgraphics Plus versión 5.1 para Windows (Statistical Graphics Corp., Herndon, Estados Unidos). Para analizar las prevalencias de $E$. histolytica y E. dispar se calculó la diferencia de porcentajes, mediante la prueba Z. La relación entre las variables edad, sexo y prevalencia de $E$. histolytica y E. dispar se determinó mediante el estadístico Ji cuadrado de Pearson. Un valor de $\mathrm{p}<0,05$ fue considerado como el nivel crítico de significación 16 . 


\section{Resultados y discusión}

La evaluación de infecciones parasitarias en la comunidad, demostró que la población está altamente infectada por enteroparásitos: (177/204) $86,77 \%$ de prevalencia general (Tabla 1). Los parásitos más frecuentemente observados fueron protozoarios, algunos patógenos para el humano y otros relacionados con el fecalismo.

La prevalencia de E. histolytica/E. dispar detectada por examen microscópico fue de 20,58\% $(42 / 204)$. Otros estudios realizados en comunidades indígenas e instituciones educativas del Estado Zulia reflejan valores similares, que oscilan entre $7,3 \%$ y $27 \% 17,18,19$. No se observaron trofozoítos hematófagos, por lo que en ningún caso pudo concluirse la presencia de E. histolytica mediante este procedimiento.

El reconocimiento de E. histolytica como especie patógena y E. dispar como especie no-patógena, y su clasificación como especies separadas, pero microscópicamente indistinguibles, han inducido a la Organización Mundial de la Salud (OMS) a recomendar el desarrollo y aplicación de métodos específicos para el diagnóstico de E. histolytica 20. Diversas publicaciones han reseñado al PCR como el método más sensible y específico para el diagnóstico de la amibiasis $15,21,22,23,24$ y lo han propuesto como la "prueba de oro” para determinar esta infección.
La técnica de PCR descrita aquí, demostró una segura detección y diferenciación de las dos especies que componen el complejo E. histolytica/E. dispar, mediante la extracción del ADN directamente de las muestras fecales sin efectuar cultivos previos (Figura 1). La sensibilidad y especificidad del PCR para el diagnóstico de $E$. histolytica fue del $87 \%$ y $91 \%$ respectivamente; mientras que para E. dispar fue del $92 \%$ y $89 \%$.

Los resultados del ensayo de PCR aplicado a las muestras estudiadas se muestran en el Tabla 2. La especie E. histolytica fue detectada en $22 \mathrm{de}$ 204 muestras fecales $(10,78 \%)$, E. dispar fue observada en 16 muestras $(7,84 \%)$ y ambas especies de Entamoeba fueron detectadas en 9 muestras $(4,41 \%)$. La prevalencia total de infección por E. histolytica $[(\mathrm{Eh}+(\mathrm{Eh}+\mathrm{Ed})]$ en la comunidad estudiada, 31 casos $(15,19 \%)$ fue mayor que la infección por E. dispar [(Ed+(Eh+Ed)], 25 casos $(12,25 \%)$. La ocurrencia de infecciones mixtas entre E. histolytica y $E$. dispar ha sido reportada previamente ${ }^{9}$. Los resultados de la prueba $\mathrm{Z}$ ( p $<0,01$ ) demostraron que la frecuencia de $E$. histolytica es significativa para esta población. Aunque muchos autores 9,10,11,21,25,26,27,28,29,30 señalan una mayor prevalencia de E. dispar con relación a E. histolytica, el hallazgo de un mayor número de casos de esta última $(15,19 \%)$ no resulta sorprendente para esta comunidad, en virtud de las deplorables condiciones de higie-

Tabla 1

Prevalencia de especies parasitarias identificadas en las muestras de heces por microscopía óptica *

\begin{tabular}{|c|c|c|}
\hline Especies parasitarias & $\mathbf{n}$ & $\%$ \\
\hline \multicolumn{3}{|l|}{ Protozoarios } \\
\hline Blastocystis hominis & 110 & 53,92 \\
\hline Entamoeba coli & 43 & 21,08 \\
\hline Complejo E. histolytica/E. dispar & 42 & 20,58 \\
\hline Giardia lamblia & 40 & 19,61 \\
\hline Endolimax nana & 26 & 12,75 \\
\hline Chilomastix mesnili & 7 & 3,43 \\
\hline lodamoeba butschlii & 4 & 1,96 \\
\hline Pentatrichomonas hominis & 3 & 1,47 \\
\hline \multicolumn{3}{|l|}{ Helmintos } \\
\hline Trichuris trichiura & 88 & 43,14 \\
\hline Ascaris lumbricoides & 72 & 35,29 \\
\hline Hymenolepis nana & 10 & 4,90 \\
\hline Strongyloides stercoralis ** & 5 & 2,45 \\
\hline Enterobius vermicularis ** & 4 & 1,96 \\
\hline Ancylostomideos & 1 & 0,49 \\
\hline
\end{tabular}

* Incluidas las asociaciones parasitarias

** Valores obtenidos sin la utilización de técnicas específicas para el diagnóstico de estos parásitos. 
Figura 1

Resultados de la amplificación por PCR.

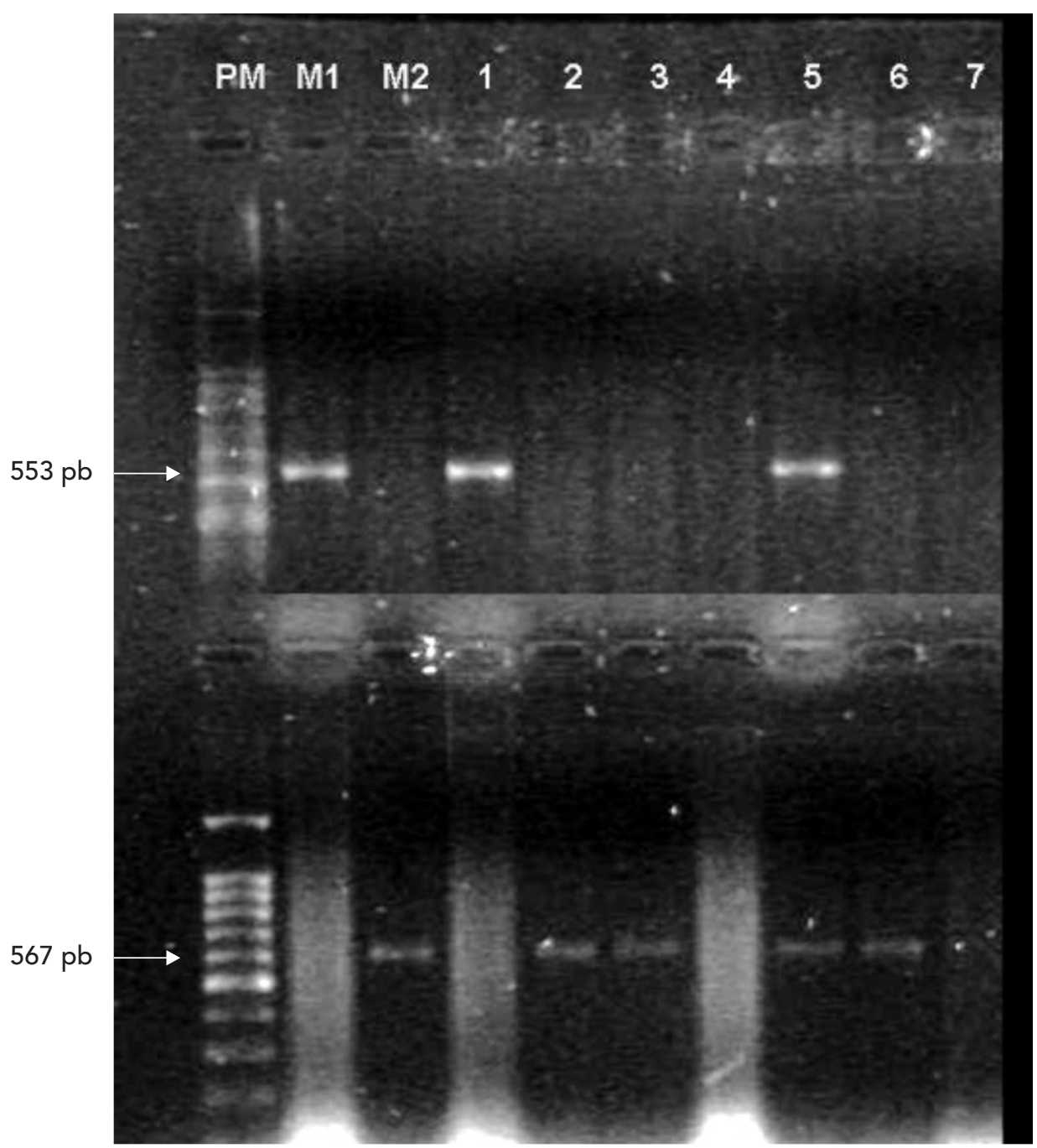

Identificación por PCR de E. histolytica y E. dispar. PM: marcador de peso molecular; M1: control de referencia de

E. histolytica; M2: control de referencia de E. dispar; carriles 1 al 7: ADN extraído de muestras de heces de pacientes, puede notarse que la muestra 5 poseía ambas especies. Arriba: amplificación por PCR, utilizando oligonucleótidos SRPEh 5/3, 553pb (específicos de E. histolytica). Abajo: productos de amplificación, obtenidos utilizando oligonucleótidos SRPEd 5/3, 567pb (específicos de E. dispar)

ne y salubridad observadas, y alerta sobre el potencial problema de salud de la amibiasis, como factor de morbilidad y mortalidad en esta parroquia. La mayoría de los individuos que viven en palafitos, acostumbran arrojar sus excretas al agua, bañarse en ellas y luego reutilizar estas mismas aguas en sus viviendas. En Venezuela, sólo existe un reporte previo que refiere la utili- zación de técnicas discriminatorias entre ambas amibas. Mora et al. 31 estudiaron mediante nested-multiplex PCR, 428 pacientes con síntomas gastrointestinales, encontrando una prevalencia de E. histolytica de 6,31\%, 4,44\% de E. dispar y 4 casos de infección mixta.

Aunque otros autores han referido la presencia de sangre en las muestras con E. histolytica 32,33 ; 
Resultados de la técnica de PCR * aplicada a las muestras de heces.

\begin{tabular}{lcc}
\hline Especie de parásito & $\mathbf{n}$ & $\%$ \\
\hline E. histolytica & $22 * \star$ & 10,78 \\
E. dispar & 16 & 7,84 \\
Infección mixta con E. histolytica y E. dispar & 9 & 4,41 \\
Negativas para ambas amibas & 157 & 76,96 \\
Total & 204 & 100,00
\end{tabular}

* PCR con los primers: SRPEh y SRPEd;

** Diferente significativamente de muestras negativas $(p<0,01)$ al aplicar la prueba $Z$.

en la presente investigación, sólo un paciente infectado con E. histolytica (1/31), presentó sangre en la muestra fecal al momento del examen macroscópico, por lo que no se pudo efectuar correlación entre estas variables. Es posible justificar la ausencia de sangre en las heces de los pacientes incluidos en este estudio, si para el momento en que los individuos entregaron su muestra, el parásito todavía no hubiere invadido la mucosa intestinal.

En general, se observó un elevado número de infecciones múltiples (poliparasitismo) entre los individuos de la comunidad $(66,17 \%)$. Cuando se analizan los casos que resultaron positivos por PCR, los protozoarios más frecuentemente asociados a E. histolytica fueron Blastocystis hominis (74,19\%), E. coli (41,93\%) y Giardia lamblia (22,58\%). En los individuos con E. dispar se presentó asociación con las mismas especies parasitarias y además con E. nana.

Algunas publicaciones refieren a E. coli como uno de los principales organismos asociados a infecciones por E. histolytica y han sugerido que debe existir un mecanismo común de transmisión o una susceptibilidad específica para estas parasitosis 9. Rivera et al. 11 estudiaron la distribución de E. histolytica y E. dispar en el norte de Filipinas y detectaron una fuerte asociación entre E. coli y la infección con E. histolytica/E. dispar.

No se observó diferencia significativa entre los porcentajes globales de las amibas estudiadas y el grupo de edad al que pertenecían los individuos ( $p>0,05)$. Resultados similares fueron obtenidos por Povoa et al. 34, al estudiar la prevalencia de E. histolytica en Brasil, mediante la detección de coproantígenos (ELISA). A pesar no existir diferencias importantes por grupo etario, se observó la ausencia de casos de amibiasis en lactantes menores y mayores, lo que se relaciona con reportes previos. Silva et al. 35 encontraron una mayor prevalencia de E. histolytica en el grupo de individuos mayores de 14 años, al estudiar una población en Brasil, mediante diversas técnicas.

Es importante destacar la ausencia de casos de amibiasis en los menores de dos años de edad, ya que ninguno estuvo parasitado con E. histolytica, E. dispar o ambas (Tabla 3). Es posible que en este grupo efectivamente haya una baja prevalencia de infección, pero el escaso número de individuos estudiados no permite obtener resultados concluyentes para este grupo de edad. Por otro lado, esta situación puede explicarse por los cuidados maternos que generalmente reciben los niños desde recién nacidos hasta aproximadamente los 20 meses de edad. Posteriormente, los niños llegan a tener un mayor contacto con el medio ambiente contaminado y por tal motivo se incrementa la probabilidad de adquirir la infección. Este señalamiento es importante, porque en nuestro medio se aprecia con preocupación, un elevado reporte de casos de amibiasis en los niños menores de dos años de edad. El Anuario de Mortalidad del año 200536 señala 114 muertes por amibiasis en el país, de las cuales 23 ocurrieron en menores de dos años. La realización de técnicas más sensibles y específicas para el diagnóstico de la amibiasis colaborará significativamente en el esclarecimiento de esta situación. El mayor número de individuos parasitados con $E$. histolytica y E. dispar se presentó en el grupo de 7-12 años. Rivera et al. 11 obtuvieron resultados similares, ya que, tampoco observaron diferencias entre los grupos etarios, pero sí una mayor prevalencia de estas amibas en los individuos de 5-14 años de edad.

De los 204 individuos estudiados, 94 pertenecían al sexo masculino y 110 al sexo femenino. De las 47 muestras que resultaron positivas para las amibas mediante PCR (34,04\%), 31 (65,96\%) especímenes pertenecían a individuos del sexo femenino y 16 al sexo masculino. En el sexo femenino la prevalencia de las amibas fue la siguiente: 
Frecuencia de las especies de amibas por grupo etario.

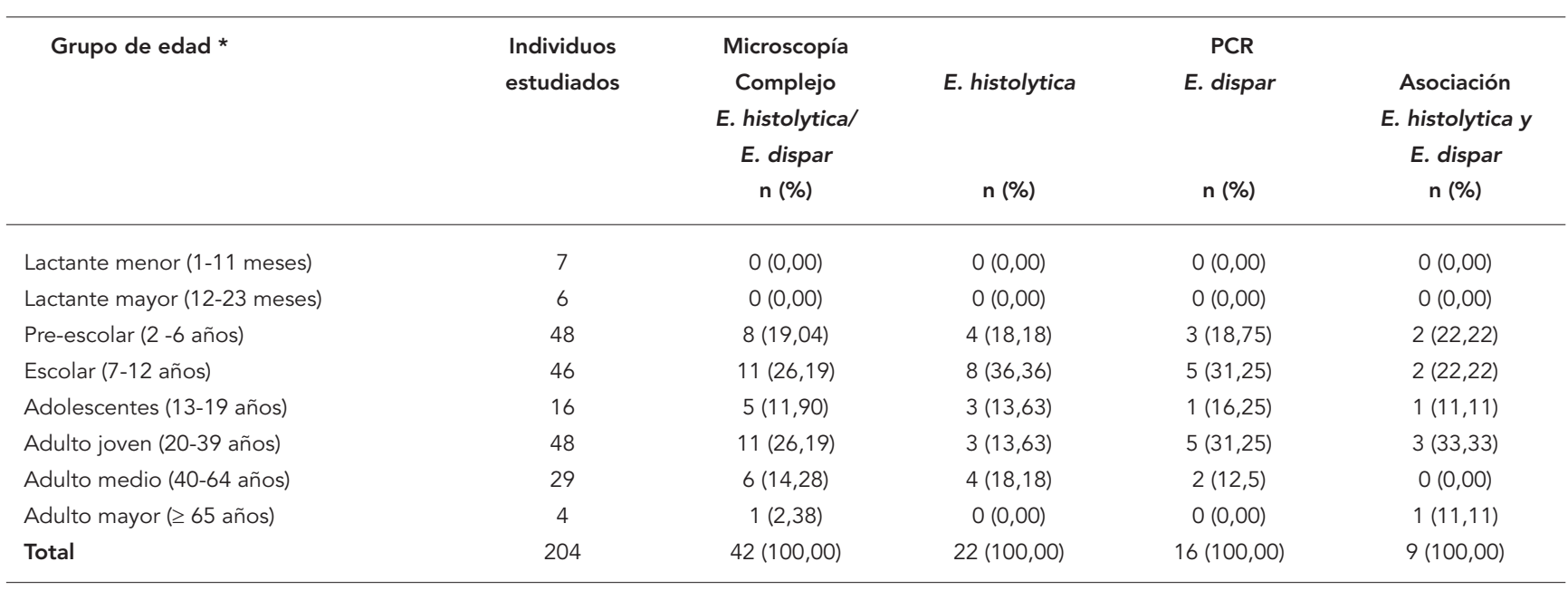

Ji cuadrado $(\chi 2)=8,5155 ; p=0,9015$ (no significativo); intervalo de confianza: 0,3-1,3.

* Clasificación según Masalán \& Gonzalez 37.

13 portadoras de E. histolytica, 12 con E. dispary 6 presentaban infección mixta. En el caso de los hombres, 9 muestras amplificaron para E. histolytica, 4 para E. dispar y 3 para ambas especies de amibas. El análisis estadístico demostró que no había diferencia significativa entre la frecuencia de las amibas y el sexo. Al igual que otros estudios que reportan una prevalencia de infecciones por E. histolytica equivalente entre hombres y mujeres 11 .

\section{Resumen}

La identificación diferencial de Entamoeba histolytica $y$ Entamoeba dispar es esencial para un tratamiento adecuado del paciente y con fines epidemiológicos. Para determinar la prevalencia de E. histolytica $y \mathrm{E}$. dispar se estandarizó y aplicó un ensayo de PCR, utilizando oligonucleótidos específicos para cada especie. 204 muestras de heces de individuos de la comunidad de Santa Rosa de Agua (Municipio Maracaibo, Estado Zulia, Venezuela), fueron analizadas a través del examen directo con SSF (0,85\%) y lugol, concentrado de formol-éter y PCR. Al examen microscópico, 42 individuos (20,58\%) presentaron formas evolutivas del complejo E. histolytica/E. dispar; mientras que la técnica
La diferenciación de especies por PCR es una herramienta necesaria y de gran valor para el diagnóstico de la amibiasis, pues le permite al clínico discriminar las verdaderas infecciones por E. histolytica y evitar los tratamientos innecesarios cuando E. dispar está presente. de PCR evidenció un total de 47 casos positivos a estas amibas; de los cuales 22 eran portadores de E. histolytica (10,78\%), 16 (7,84\%) de E. dispar y 9 (4,41\%) presentaron infección mixta. No hubo diferencia significativa al relacionar las variables sexo y presencia de E. histolytica y/o E. dispar, ni con los grupos etarios. No existieron casos de estas amibas, en los menores de 2 años. La frecuencia observada de E. histolytica (31/204), demuestra el carácter endémico de la amibiasis en esta comunidad.

Entamoeba; Parásitos; Heces; Microscopía; Reaceión en Cadena de la Polimerasa 


\section{Colaboradores}

Z. Rivero participó de la redacción del artículo, recolección y procesamiento parasitológico de las muestras. A. Bracho participó de la redacción del artículo, recolección, procesamiento parasitológico de las muestras y procesamiento PCR. M. Calchi e I. Díaz contribuyeron en la recolección y procesamiento parasitológico de las muestras. E. Acurero, A. Maldonado y G. Chourio realizaron el procesamiento parasitológico de las muestras. N. Arráiz participó del procesamiento PCR y de la redacción del artículo. G. Corzo contribuyó en el cálculo de $\mathrm{n}$ y análisis estadístico de los datos. Todos los autores revisaron, aportaron y aprobaron la versión final.

\section{Agradecimientos}

Los autores agradecen al Consejo de Desarrollo Científico y Humanístico (CONDES, Venezuela) por el financiamiento del programa (VAC-CONDES-CC-0216-05). Además, a la Dra. Ivonne Qvamstrong del Centers for Disease Control and Prevention (Estados Unidos), por la donación del ADN de Entamoeba dispar; así como a la Dra. Haydee Urdaneta (Instituto de Inmunología Clínica, Universidad de los Andes, Venezuela) por proveernos de la cepa de Entamoeba histolytica. A Gilbert Corzo por el cálculo de $\mathrm{n}$ y análisis estadístico de los datos.

\section{Referencias}

1. Martínez-Palomo A, González-Robles A, De La Torre M. Selective agglutination of pathogenic strains of Entamoeba histolytica induced by con A. Nat New Biol 1973; 245:186-7.

2. Sargeaunt PG, Willians JE, Grene JD. The differentiation of invasive and non-invasive Entamoeba histolytica by isoenzyme electrophoresis. Trans R Soc Trop Med Hyg 1978; 72:519-21.

3. Petri Jr. WA, Clark CG, Diamond LS. Host-parasite relationships in amebiasis: conference report. J Infect Dis 1994; 169:483-4.

4. Brumpt E. Etude sommaire de l'Entamoeba dispar n.s.p. amibe à kystes quadrine de l'homme. Bulletin de l'Academie de Médecine 1925; 94:943-52.

5. World Health Organization/Pan American Health Organization/United Nations Educational, Scientific and Cultural Organization. Report of a consultation of experts on amoebiasis. Mexico DF: World Health Organization/Pan American Health Organization/United Nations Educational, Scientific and Cultural Organization; 1997.

6. Shibayama-Hernández H, Pedroza-Gómez J, Rivero-Baños B, Shibayama M, Serrano-Luna J, Tsutsu$\mathrm{mi}$ V. A simple stool concentration method for the detection and preservation of the vegetative forms of Entamoeba histolytica/Entamoeba dispar. Arch Med Res 2000; 31:S30-1.
7. Murray P, Baron E, Jorgensen J, Pealler M, Yolken R Manual of clinical microbiology. v. 2. 8th $^{\text {thd. Wash- }}$ ington DC: ASM Press; 2003.

8. Ritchie L. An ether sedimentation technique for routine stool examination. Bull U S Army Med Dep 1948; 8:326.

9. Núñez Y, Fernández M, Torres D, Silva J, Montano L, Maestre J, et al. Multiplex polymerase chain reaction amplification and differentiation of Entamoeba histolytica and Entameoba dispar DNA from stool samples. Am J Trop Med Hyg 2001; 64:293-7.

10. Ramos F, Morán P, González E, García G, Ramiro M, Gómez A, et al. Entamoeba histolytica and Entamoeba dispar: prevalence infection in a rural Mexican community. Exp Parasitol 2005; 110: 327-30.

11. Rivera W, Tachibana H, Kanbara H. Field study on the distribution of Entamoeba histolytica and Entamoeba dispar in the Northern Philippines as detected by the polymerase chain reaction. Am J Trop Med Hyg 1998; 59:916-21.

12. Stanley L, Blanchard L, Johnson N, Foster L, KunzJenkins C, Zhang T, et al. Immunogenicity of the recombinant Serine Rich Entamoeba histolytica Protein (SREHP) amebiasis vaccine in the African green monkey. Vaccine 1995; 13:947-51. 
13. Altschul SF, Gish W, Miller W, Myers EW, Lipman DJ. Basic local alignment search tool. J Mol Biol 1990; 215:403-10.

14. Altschul SF, Madden TL, Schaffer AA, Zhang J, Zhang Z, Miller W, et al. Gapped BLAST and PSIBLAST: a new generation of protein database search programs. Nucleic Acids Res 1997; 25: 3389-402.

15. Blessmann J, Buss H, Ton Un P, Dinh B, Viet Ngo Q, Le Van A, et al. Real-time PCR for detection and differentiation of Entamoeba histolytica and Entamoeba dispar in fecal samples. J Clin Microbiol 2002; 40:4413-7.

16. Daniel W. Bioestadística. Base para el análisis de las ciencias de la salud. 4a Ed. México DF: Limusa Wiley; 2002.

17. Rivero Z, Díaz I, Acurero E, Camacho MC, Medina M, Ríos L. Prevalencia de Parásitos Intestinales en Escolares de 5 a 10 años de un Instituto del Municipio Maracaibo. Estado Zulia. Kasmera 2001; 29:153-70.

18. Díaz I, Rivero Z, Bracho A, Castellanos M, Acurero E, Calchi M, et al. Prevalencia de enteroparásitos en niños de la etnia Yukpa de Toromo, Estado Zulia, Venezuela. Rev Méd Chil 2006; 134:72-8.

19. Chacín-Bonilla L, Dikdan Y. Prevalencia de Entamoeba histolytica y otros parásitos intestinales en una comunidad suburbana de Maracaibo. Invest Clin 1981; 22:185-203.

20. World Health Organization. Amoebiasis. Wkly Epidemiol Rec 1997; 72:97-100

21. Evangelopoulos A, Legakis N, Vakalis N. Microscopy, PCR and ELISA applied to the epidemiology of amoebiasis in Greece. Parasitol Int 2001; 50:185-9.

22. Troll H, Marti H, Weiss N. Simple differential detection of Entamoeba histolytica y Entamoeba dispar in fresh stool specimens by sodium acetateacetc acid-formalin concentration and PCR. J Clin Microbiol 1997; 35:1701-5.

23. Morán P, Ramos F, Ramiro M, Curiel O, Gonzalez E, Valadez A, et al. Entamoeba histolytica and/or Entamoeba dispar: infection frequency in HIV/ AIDS patients in Mexico City. Exp Parasitol 2005; 110:331-4.

24. el-Hamshary EM, el-Shewy KA, Hezagy MM, Zakaria H. Selective identification of the pathogenic E. histolytica in fresh stool simples using polymerase chain reaction (PCR). J Egypt Soc Parasitol 2004; 34:611-20.

25. Gonin P, Trudel L. Detection and differentiation of Entamoeba histolytica and Entamoeba dispar isolates in clinical samples by PCR and enzymelinked immunosorbent assay. J Clin Microbiol 2003; 41:237-41.

26. Pinheiro SM, Carneiro RM, Aca IS, Irmao JI, Morais MA, Coimbra MR, et al. Determination of the prevalence of Entamoeba histolytica and E. dispar in the Pernambuco State of Northeastern Brazil by a polymerase chain reaction. Am J Trop Med Hyg 2004; 70:221-4.
27. Calderaro A, Gorrini Ch, Bommezzadri S, Piccolo G, Dettori G, Chezzi C. Entamoeba histolytica and Entamoeba dispar: comparison of two PCR assays for diagnosis in a non-endemic setting. Trans $\mathrm{R}$ Soc Trop Med Hyg 2006; 100:450-7.

28. Visser L, Verweij J, Van M, Edeling W, Clreinx J, Polderman A. Diagnostic methods for differentiation of Entamoeba histolytica and Entamoeba dispar in carries: performance and clinical implications in a non-endemic setting. Int J Med Microbiol 2006; 296:397-403.

29. Verweij J, Oostvogel F, Brienen E, Nang-Beifubah A, Ziem J, Polderman A. Prevalence of Entamoeba histolytica and Entamoeba dispar in northern Ghana. Trop Med Int Health 2003; 8:1153-6.

30. Walderich B, Weber A, Knobloch J. Differentiation of Entamoeba histolytica and Entamoeba dispar from German travelers and residents of endemic areas. Am J Trop Hyg 1997; 57:70-4.

31. Mora L, García A, De Donato M, Urdaneta H. Estudio epidemiológico y molecular de Entamoeba histolytica y Entamoeba dispar en pacientes con diarrea en Cumaná, Estado Sucre, Venezuela. Invest Clin 2008; en prensa.

32. Sánchez-Guillén M, Pérez-Fuentes R, Salgado-Rosas H, Ruiz-Argüelles A, Ackers J, Shire A, et al. Differentiation of Entamoeba histolytica/Entamoeba dispar by PCR and their correlation with humoral and cellular immunity in individuals with clinical variants of amoebiasis. Am J Trop Med Hyg 2002; 66:731-7.

33. Mora L, García A, De Donato M. Prevalencia del complejo Entamoeba histolytica/Entamoeba dispar en pacientes con síntomas gastrointestinales de diarrea procedentes de Cumaná, Estado Sucre. Kasmera 2005; 33:36-45.

34. Póvoa MM, Arruda JEG, Silva MCM, Bichara CNC, Esteves P, Gabbay YB, et al. Diagnóstico de amebíase intestinal utilizando métodos coproscópicos e imunológicos em amostra da população da área metropolitana de Belém, Pará, Brasil. Cad Saúde Publica 2000; 16:843-6.

35. Silva MCM, Monteiro CSP, Araújo BAV, Sillva JV, Póvoa MM. Determinação da infecção por Entamoeba histolytica em residentes da área metropolitana de Belém, Pará, Brazil, utilizando ensaio imunoenzimático (ELISA) para detecção de antígenos. Cad Saúde Pública 2005; 21:969-73.

36. Dirección de Información Social y Estadísticas, Dirección General de Epidemiología, Ministerio de Salud. Anuario de mortalidad 2005. Caracas: Ministerio de Salud; 2006.

37. Masalán M, González R. Autocuidado del ciclo vital. http://www.puc.cl/sw_educ/enferm/ciclo/index. html (accedido el Dic/2003).
Recibido el 28/Mar/2008
Versión final presentada el 19/Jun/2008
Aprobado el 01/Jul/2008 